\title{
Thirteenth International Congress on Mathematical Education: An Introduction
}

\author{
Gabriele Kaiser
}

\begin{abstract}
The paper describes the vision of the 13th International Congress on Mathematical Education (ICME-13), accompanied by detailed elaborations on the structure of ICME-13 and important data.
\end{abstract}

The 13th International Congress on Mathematical Education (ICME-13) took place from 24 to 31 July 2016 in Hamburg, hosted by the Gesellschaft für Didaktik der Mathematik (Society of Didactics of Mathematics) under the auspices of the International Commission on Mathematical Instruction (ICMI).

ICME-13 had 3486 participants, with 360 accompanying persons, making it the largest ICME so far. Congress participants came from 105 countries, i.e., more than half of the countries in the world were present. Two hundred and fifty teachers attended additional activities that took place during ICME-13. Directly before the beginning of ICME-13, 450 early-career researchers attended a day-long specific programme. These high participation numbers strongly indicate that mathematics education has become a widely accepted scientific discipline with its own structure and standards. Furthermore, it documents the growing international community of mathematics educators.

At the opening ceremony, the five ICMI awards were presented to Michèle Artigue and Alan Bishop (Felix Klein award), Jill Adler and Frederick Leung (Hans Freudenthal award), Hugh Burkhardt and Malcolm Swan (Emma Castelnuovo award). Their presentations can be found in these proceedings together with a short introduction by Carolyn Kieran and Jeremy Kilpatrick.

The heart of the congress consisted of 54 Topic Study Groups, devoted to major themes of mathematics education, in which 745 presentations were given. In attached oral communications, 931 shorter papers were presented, complemented by 533 posters presented in two sessions.

\footnotetext{
G. Kaiser $(\bowtie)$

Universität Hamburg (ICME-13), Hamburg, Germany

e-mail: Gabriele.Kaiser@uni-hamburg.de 
Two plenary panels presented their points of view on:

- International comparative studies in mathematics: Lessons for improving students' learning, with Jinfa Cai (Chair), Ida Mok, Vijay Reddy and Kaye Stacey

- Transitions in mathematics education, with Ghislaine Gueudet (Chair), Marianna Bosch, Andrea diSessa, Oh Nam Kwon and Lieven Verschaffel.

Four plenary lectures took place:

- Uncovering the special mathematical work of teaching, by Deborah Loewenberg Ball

- Mathematics education in its cultural context: Plus and minus 30 years, by Bill Barton

- Mathematics classroom studies: Multiple windows and perspectives, by Berinderjeet Kaur

- "What is mathematics?" and why we should ask, where one should learn that, and who can teach it, by Günter M. Ziegler.

In addition, 64 invited lectures were given by scholars from all over the world presenting the state of the art in their research field. The second volume of the proceedings of ICME-13 will publish these lectures.

38 discussion groups and 42 workshops initiated by congress participants were offered in which a great variety of themes were discussed, fostering international collaboration.

Reflecting specific ICMI traditions, five ICMI survey teams described the state of the art on the following themes:

- Distance learning, blended learning, e-learning in mathematics (chaired by Marcelo Borba)

- Conceptualisation of the role of competencies, knowing and knowledge in mathematics education research (chaired by Mogens Niss)

- Assistance of students with mathematical learning difficulties: How can research support practice? (chaired by Petra Scherer)

- Teachers working and learning through collaboration (chaired by Barbara Jaworski)

- Recent research on geometry education (chaired by Nathalie Sinclair).

The first results of these survey teams were published as Issue 5 in 2016 of ZDM Mathematics Education (http://link.springer.com/journal/volumesAndIssues/11858); short versions of these reports can be found in this volume of the proceedings.

Three ICMI studies presented results that already have been published or will be published by Springer in the new ICMI Study Series:

- ICMI Study 21 on mathematics education and language diversity (Richard Barwell et al.)

- ICMI Study 22 on task design (Anne Watson and Minoru Ohtani)

- ICMI Study 23 on primary mathematics study of whole numbers (Mariolina Bartolini Bussi and Xuhua Sun). 
In addition, six national presentations were given describing the situation of mathematics education and its scholarly discussion in Argentina, Brazil, Ireland, Japan, the Lower Mekong Sub-Region and Turkey. Short descriptions of the presentations are given in this volume.

Apart of these impressive figures, the historical development is important: In 1976 another ICME had already taken place in Germany, namely the Third International Congress on Mathematical Education (ICME-3), which was held in Karlsruhe. The organisation of ICME-3 in 1976 reflected the German tradition of collaboration between mathematicians and mathematics educators, with mathematics educator Hans-Georg Steiner as Chair of the International Programme Committee and mathematician Heinz Kunle as Chief Organiser of the congress. The strong collaboration between mathematics and mathematics education has been further developed and the Deutsche Mathematiker-Vereinigung (German Mathematical Society) has strongly supported ICME-13 since the very beginning. The German community is the first international mathematics educational community to host an ICME a second time.

On the occasion of this special event a thematic afternoon was carried out devoted to the description of the development in the last 40 years from a European and a historical perspective. The thematic afternoon's topics were Selected European Didactic Traditions, German-speaking Traditions and the Legacy of Felix Klein. These special activities aimed to show the development of the German mathematics education discussion over the last 40 years, embedding it in a continental European context and in its historical development.

The German-speaking countries share many common roots with the continental European didactic traditions of mathematics education, including common pedagogical and philosophical traditions. These strong connections within the European tradition of didactics are already apparent in the word Didaktik in German, didactique in French, didáctica in Spanish, Italian and Czech, didactiek in Dutch, Danish and Swedish. This Didaktik-tradition can be found in many European countries and has as a common core a theoretical foundation of education with a strong normative orientation. This tradition goes back to the Czech pedagogue Comenius with his Didactica Magna (The Great Didactic). Comenius, who developed still modern approaches to education, is considered the father of modern education (Hudson \& Meyer, 2011). Four distinctive features of these modern continental European traditions were identified within the selected European didactic traditions at this thematic afternoon: the strong connection between mathematics and mathematicians, the key roles of both theory and design activities for learning and teaching environments and a firm basis on empirical research. A short description of this topic can be found in these proceedings (Blum et al.), while a detailed description will be given in a book coming out in the series of ICME-13 monographs.

The second strand displayed the German-speaking traditions, which include Austria and Switzerland in addition to Germany. This strand of the discussion is especially connected to a particular approach to didactics of mathematics that is 
subject bound and strongly oriented towards mathematics (so-called Stoffdidaktik). This approach was already evident in Arnold Kirsch's keynote lecture, Aspects of Simplification in Mathematics Teaching, at ICME-3 in Karlsruhe and has been further developed in the last 40 years (Kirsch, 1977). Other distinctive features are related to applications and modelling, which play a prominent role in German mathematics education and were described at ICME-12 in Seoul by Werner Blum in his plenary talk (Blum, 2015). Another important feature of the German-speaking tradition discussion is the approach to mathematics education as design science aiming to bridge the gap between theory and practice, which was put forward by the plenary talk of Erich Wittmann at ICME-9 in Tokyo (Wittmann, 2004). A short description of these presentations can be found in these proceedings (Jahnke et al.), while a detailed description will be given in a book coming out in the series of ICME-13 monographs.

The third strand of these special activities, the Legacy of Felix Klein, referred to the historical roots of German-speaking mathematics education. Felix Klein, the founding president of ICMI, shaped mathematics education not only nationally but internationally in several respects. His legacy was reflected upon from three perspectives, the first being functional thinking as one fundamental mathematical idea structuring mathematics education from the very beginning to university. The second perspective was intuitive thinking and visualisation, which reflects the high importance of Anschauung in German mathematics education. Felix Klein developed the Modellkammer, models of mathematical phenomena, which has been promoted in other parts of the world (Schubring, 2010). The mathematical exhibition from the Mathematikum, which has been on display during ICME-13, refers with its hands-on activities strongly to this tradition. A short description of this strand can be found in these proceedings (Weigand et al.), while a detailed description will be given in a book coming out in the series of ICME-13 monographs.

The last perspective is strongly connected to Felix Klein's famous books, Elementarmathematik vom Höheren Standpunkte aus, published originally from 1902 to 1909 in German with the first volume on arithmetic, algebra and analysis, the second on geometry and the third on precision and approximation mathematics (Klein, 1902-1908). The first two volumes were published in English with the title Elementary Mathematics from an Advanced Standpoint in 1932 (Volume 1) and 1939 (Volume 2). Supported by Springer Publishing, a new translation of the first two books from Felix Klein has come out on the occasion of ICME-13, called Elementary Mathematics from a Higher Standpoint (Klein, 2016). The wording of the title has been changed from advanced to higher, taking up the critique by Kilpatrick (2008/2014) at ICME-11 of the inadequate translation (2008/2014). The translation by Gert Schubring attempts to bring the English version closer to its German original, for example, by clarifying fundamental concepts for Klein's approach that were inadequately translated, such as Anschauung, which is insufficiently translated as perception. Furthermore, the third volume, Precision Mathematics and Approximation Mathematics, which was not been available in English, has now been translated by Marta Menghini in collaboration with Anna Baccaglini-Frank. It is a huge step forward for mathematics education that this work 
is now available in a complete and adequate form, because the connection of mathematics with its applications under a higher perspective was of particular importance to Felix Klein and was his lifelong theme. Jeremy Kilpatrick states concerning the importance of this work: "Despite the many setbacks he encountered, no mathematician had a more profound influence on mathematics education as a field of scholarship and practice" (p. 27).

Apart from this thematic afternoon as distinctive feature of ICME-13, an extensive publication programme was implemented in order to develop a sustainable congress from an academic perspective. One of our aims with the publication of the ICME-13 Topical Surveys was to display the state of the art concerning specific mathematics educational themes in the style of independent handbook chapters. 26 ICME-13 Topical Surveys were published, and the important aspect of these Topical Surveys coming out before ICME-13 is that they were available as open access and hopefully formed the basis for many discussions at the congress. They displayed what we knew before the congress. The forthcoming post-congress monographs based on the papers presented within the framework of the topic study and discussion groups describe the academic outcome of ICME-13 in more detail and will hopefully contribute to a sustainable congress.

It is our strong hope that ICME-14, which will take place in Shanghai in 2020, will be able to build its work on the insights achieved and published here and can thereby strongly foster the development of knowledge on the teaching and learning of mathematics on a higher basis.

The aforementioned books from Felix Klein, Elementary Mathematics from a Higher Standpoint (2016), originated from lectures Felix Klein gave to prospective teachers. His desire in publishing these books was to develop the ability of the prospective teachers to use the rich mathematics they were learning at university as vivid stimulation for their own teaching afterwards. This strong tradition that shaped the German-speaking community has led to many activities in pre-service and in-service teacher education.

During ICME-13, three days of German-language activities for teachers were conducted in which scholars participating in ICME-13 worked with practising teachers in workshops and lectures and offered them background knowledge or new teaching ideas. These activities for teachers were supported by the MNU - Verband zur Förderung des MINT-Unterrichts (German Association for the Advancement of Mathematics and Science Education), a teacher community, which has supported ICME-13 from the very beginning.

The final characteristics of ICME-13 to be mentioned are the activities for early career researchers. Early career researchers are our future, because they have to shoulder the task to further develop the science of mathematics education and to implement these improvements at all educational levels. We have seen in the past a strong development towards higher quality standards of research. Publishing a study needs nowadays to fulfil many requirements concerning theoretical framework and methodology used. Furthermore, publications have become more and more important in the last years. Therefore, ICME-13 held an early career researcher day with 450 participants where thematic surveys were presented and 
empirical methodologies prominent in mathematics education were discussed. In addition, descriptions of selected mathematics educational journals by the editors of those journals were followed by workshops on academic publishing and writing. These kinds of activities are highly necessary and should in the future be an integral part of ICMEs.

Finally, it is the tradition at each ICME to devote $10 \%$ of the congress fees to a solidarity grant in order to support scholars from less affluent countries. With the support of the Federal Ministry of Education and Research and the Bosch Foundation, ICME-13 was able to spend nearly $9 \%$ of the whole congress budget, about 230,000 Euros, for scholars from less affluent countries, supporting 223 participants from 66 countries. A special focus was set on African scholars; ICME-13 was able to support 50 African scholars from 19 countries. These efforts reflect the strong will of the German society to express solidarity with less wealthy regions and take responsibility for helping those regions. It will be our task to continue these efforts to insure equitable access not only to mathematics instruction in school for all people but also to the academic discussion on mathematics education for scholars all over the world, making an ICME a unique international experience.

ICME-13 has been the biggest ICME so far and has allowed many scholars from all over the world to participate actively. It will be our ongoing task to broaden the participation in ICMEs and to encourage scholars from all over the world to engage in and enrich all future ICMEs.

Acknowledgements I would like to thank Lena Pankow for her strong and continuing support not only during the congress ICME-13, but in the work for this volume as well.

\section{References}

Blum, W. (2015). Quality teaching of mathematical modelling: What do we know, what can we do? In S. J. Cho (Ed.), The Proceedings of the 12th International Congress on Mathematical Education (pp. 73-96). Cham: Springer.

Hudson, B., \& Meyer, M. A. (Eds.). (2011). Beyond fragmentation: Didactics, learning and teaching in Europe. Opladen: Barbara Budrich Publishers.

Kilpatrick, J. (2008/2014). A higher standpoint. Materials from ICME-11. Regular lectures (pp. 26-43). http://www.mathunion.org/fileadmin/ICMI/files/About_ICMI/Publications_ about_ICMI/ICME_11/Kilpatrick.pdf (last access 5.1.2017).

Kirsch, A. (1977). Aspects of simplification in mathematics teaching. In H. Athen \& H. Kunle (Eds.), Proceedings of the Third International Congress on Mathematical Education (pp. 98 120). Karlsruhe: Zentralblatt für Didaktik der Mathematik, Universität (West) Karlsruhe.

Klein, F. (1902-1908). Elementarmathematik vom höheren Standpunkte aus (Vol. 1-3). Berlin: Verlag von Julius Springer.

Klein, F. (2016). Elementary mathematics from a higher standpoint (Vol. 1-3) (Vol. 1-2, G. Schubring, Trans.). Vol. 3 by Martha Menghini in collaboration with Anna Baccaglini-Frank. Heidelberg: Springer.

Schubring, G. (2010). Historical comments on the use of technology and devices in ICMEs and ICMI. ZDM Mathematics Education, 42(1), 5-9. 
Wittmann, E. C. (2004). Developing mathematics in a systematic process. In H. Fujita, Y. Hashimoto, B. R. Hodgson, P. Y. Lee, S. Lerman, \& T. Sawada (Eds.), Proceedings of the Ninth International Congress on Mathematical Education (pp. 73-90). Dordrecht: Kluwer Academic Publishers.

Open Access Except where otherwise noted, this chapter is licensed under a Creative Commons Attribution 4.0 International License. To view a copy of this license, visit http://creativecommons. org/licenses/by/4.0/. 